\title{
A Comparison Between Superficial and Deep-Seated Lipomas on High-Resolution Ultrasonography: with RTE and MRI Appearances
}

\author{
Kazumi Fujioka* \\ Department of Dermatology, Fujioka Dermatological Clinic, Japan
}

*Corresponding author: Kazumi Fujioka, Department of Dermatology, Fujioka Dermatological Clinic, 1-35-10, Tamagawa, Ota-ku, Tokyo, Japan

\section{ARTICLE INFO}

Received: 豐 June 24, 2019

Published: 㹃 July 01, 2019

Citation: Kazumi Fujioka. A Comparison Between Superficial and Deep-Seated Lipomas on High-Resolution Ultrasonography: with RTE and MRI Appearances. Biomed J Sci \& Tech Res 19(2)-2019. BJSTR. MS.ID.003278.

Keywords: Real-Time Tissue Elastography; Superficial Lipoma; Deep-Seated Lipoma; High-Resolution Ultrasonography; Magnetic Resonance Image

\begin{abstract}
Soft-tissue lipomas are the most common type of benign mesenchymal tumors and are classified into two types, namely superficial and deep lesions. Superficial, ordinary lipomas occur in the subcutaneous tissues, while deep-seated lipomas occur to the investing fascia. There have been several reports of the superficial lipoma on ultrasonography (US), while a few reports, rare entity, deep-seated lipomas have been studied. In this article, a comparison between superficial and deep-seated lipomas on US features including gray-scale US, color Doppler US and Real-Time Tissue Elastography (RTE) with magnetic resonance image (MRI) appearances was reviewed in detail. The author will suggest that superficial lipoma is usually hyperechoic solid mass without posterior echo enhancement on gray scale US and shows soft nature, having high elasticity on RTE. It is plausible that both superficial and deep-seated lipomas show echogenic lines on grayscale US. The author will suggest that deep-seated lipoma shows moderately soft nature on RTE.
\end{abstract}

\section{Introduction}

In recently years, dermatologic ultrasound imaging has been rapidly developed [1]. DERMUS (Dermatologic Ultrasound), the international working group, was formed and provided the guidelines for performing dermatologic ultrasound examinations [1] and proposed for an assessment training program [2]. Lipoma, common entity is regarded as level 1 content of the training program by DERMUS [2]. Soft-tissue lipomas are the most common type of benign mesenchymal tumors and are classified into two types, namely superficial and deep types. Superficial lipomas occur in the subcutaneous tissues, while deep-seated types occur deep to the investing fascia. Histologically, both subcutaneous and deepseated lipomas are comprised of mature adipose cells. Deep-seated lipomas are less common than ordinary superficial types [3]. In this article, the current knowledge of superficial and deep-seated lipomas on US features including gray-scale US, color Doppler US and RTE with MRI findings will be reviewed in detail.

\section{Dermatologic Ultrasound}

Dermatologic ultrasound imaging has been rapidly growing in recently years because of the advent of high-resolution multifrequency transducers and multichannel color Doppler machines [1]. The minimum frequency recommended for performing dermatologic examinations by DERMUS was $15 \mathrm{MHz}$ [2] Lipoma is considered as level 1 content of the training program by DERMUS [2]. We usually perform US examinations for dermatologic lesions with a high-resolution, broad-band (5MHz-18MHz) linear transducer (Nobulus Hitachi, Ltd. Tokyo, Japan). We have provided several studies in the dermatologic field [4-11].

\section{Soft -Tissue Lipoma}

\section{Superficial Lipoma}

Superficial lipomas are common in the subcutaneous layer, accounting for $16 \%$ to $50 \%$ of all soft tissue tumors [12]. 
Superficial lipoma occur over a wide range of ages, are most prevalent between the ages of 40 and 60 years [13], are generally found in the posterior trunk, neck and proximal extremities [14]. Cytogenetically, ordinary lipomas are characterized primarily by simple balanced chromosome aberrations [15]. The chromosome segment, 12q 13-15, where the HMGA2 gene play a role [15]. It has been also cytogenetically reported that ordinary lipoma represents the characteristic features, including rearrangement of 12q13-15. These rearrangements lead to the HMGA2 gene fusion, resulting in the neomorphic activity that predispose the neoplastic process. Lacaria et al. [16] have also indicated a rare case of pediatric lipoma with $t(9 ; 12)(p 22 ; q 14)$ and evidence of HMGA2-NFIB gene fusion.

\section{Deep-Seated Lipoma}

Deep-seated lipoma is subfascial benign mesenchymal soft tissue tumors which is consist of white mature adipose cells. They are less common than ordinary superficial types and can be intramuscular or intermuscular lipoma [3]. Intramuscular types are divided into infiltrative and well-circumscribed lipomas. It has been described that $83 \%$ were of the infiltrative and $17 \%$ were the welldefined $[3,17]$. It has been also reported that the locations of the subfascial lipomas are classified into intramuscular, intermuscular, submuscular, seromuscular and others [14]. Deep-seated lipomas usually occur in the extremities [13] and are less common than superficial type. A few studies $[3,14,18]$ and a review article [17] of this uncommon entity have been reported.

\section{Gray Scale Ultrasonographic Features}

\section{Superficial Lipoma}

Several studies [13,19-23] and a review article [24] of superficial lipoma have been reported on US. Superficial lipoma was shown as hyperechoic lesion compared with the adjacent muscle but isoechoic as compared with the adjacent subcutaneous adipose tissue on gray-scale US [13]. A hyperechoic solid mass without acoustic shadow enhancement is usually considered as a superficial lipoma. Echogenic lines, namely gently curved were represented within lipoma. Warger et al. [13] have also noted that the echogenic lines, often showing gently curved, were useful in the diagnosis of isoechoic and hypoechoic lipomas.

Lipoma usually was shown as hyperechoic solid superficial mass without acoustic shadowing, while hyperechoic superficial masses with acoustic shadowing were putatively considered as fat necrosis, foreign bodies, or fat-containing hernia. Ahuja et al. [19] have reported that US feature of head and neck lipomas represent an elliptical mass, hyperechoic relative to adjacent muscle and no posterior echo enhancement. They contain linear echogenic lines on US. It has been suggested that these soft-tissue masses are lower in reflectivity than muscle but more reflective than adjacent subcutaneous fat [24]. Rahmani et al. [24] have systematically reviewed the studies that have examined the diagnostic accuracy of ultrasound in lipomas and concluded that US tool is sensitive and specific enough to be a reasonable first line investigation in superficial lipomas.

\section{Deep-Seated Lipoma}

Clinically, deep-seated lipomas are more difficult to estimate correct diagnosis. It has been described that ultrasound characteristic of deep-seated lipomas are more varied than superficial type. They also noted that the fibrous capsule was often seen on grayscale US in superficial lipomas, while it was not detected in intramuscular type [24]. Paunipagar et al. [14] noted that deep-seated lipoma tends to show roundish or oblong shape. They also described that deep-seated type tend to have well-defined margin, hyperechoic to muscle and fine internal echoes. Thin internal echoes parallel to the long axis of the tumors comprising three patterns were suggested, indicating the significant features of accurate diagnosis in deep-seated lipomas. This case was diagnosed as a deep-seated lipoma using high-resolution US and MRI procedures in the back in a 66-year-old man. This lesion was located at the subfascial region. Well-defined margin, hyperechoic compared with the adjacent muscle and echogenic lines in the mass were obviously depicted on gray-scale US (Figure 1a).

\section{Color Doppler Ultrasonographic Features}

There have been some reports of superficial lipoma on color Doppler US $[13,19]$. With respect to the deep-seated type, there was only one study. Wanger et al. [14] reported that all lipomas demonstrated minimal or no internal blood flow [13], while it is suggested that deep-seated lipomas are recognized to be more vascular than subcutaneous ones [14]. Figure 1b shows no blood flow signals in deep-seated lipoma on color Doppler US.

\section{Real-Time Tissue Elastography Features}

Real-time sonoelastography is an ultrasound-based technique using the property that the tissue strain due to compression is lower in hardness tissues [25]. RTE is widely used for the diagnosis on tissue elasticity. The author has previously reported the characteristic features of angioleiomyoma [7] and epidermal cyst $[9,11]$ on RTE in dermatologic field. On RTE, red is used to represent high elasticity, blue represents low elasticity, and yellow or green shows intermediate elasticity. Lee et al. [26] concluded that the stain ratios of lipoma, ganglia, were statistically different from epidermal cysts. Park et al. [27] described that the strain elastography score was classified into four grades (1-4) according to their elasticity; score 1 (very soft, high elasticity), score 2 (moderately soft, moderately high elasticity), score 3 (moderately hard, moderately low elasticity), and score 4 (very hard, low elasticity). They have demonstrated that lipoma on RTE showed green to orange color, suggesting grade 1 [28]. In our experience, superficial lipoma shows soft nature, high elasticity on RTE. Meanwhile, there have not been the reports of deep-seated lipoma on RTE. Figure 1c represented green color with a red color, showing moderately high elasticity in deep-seated lipoma on RTE. 


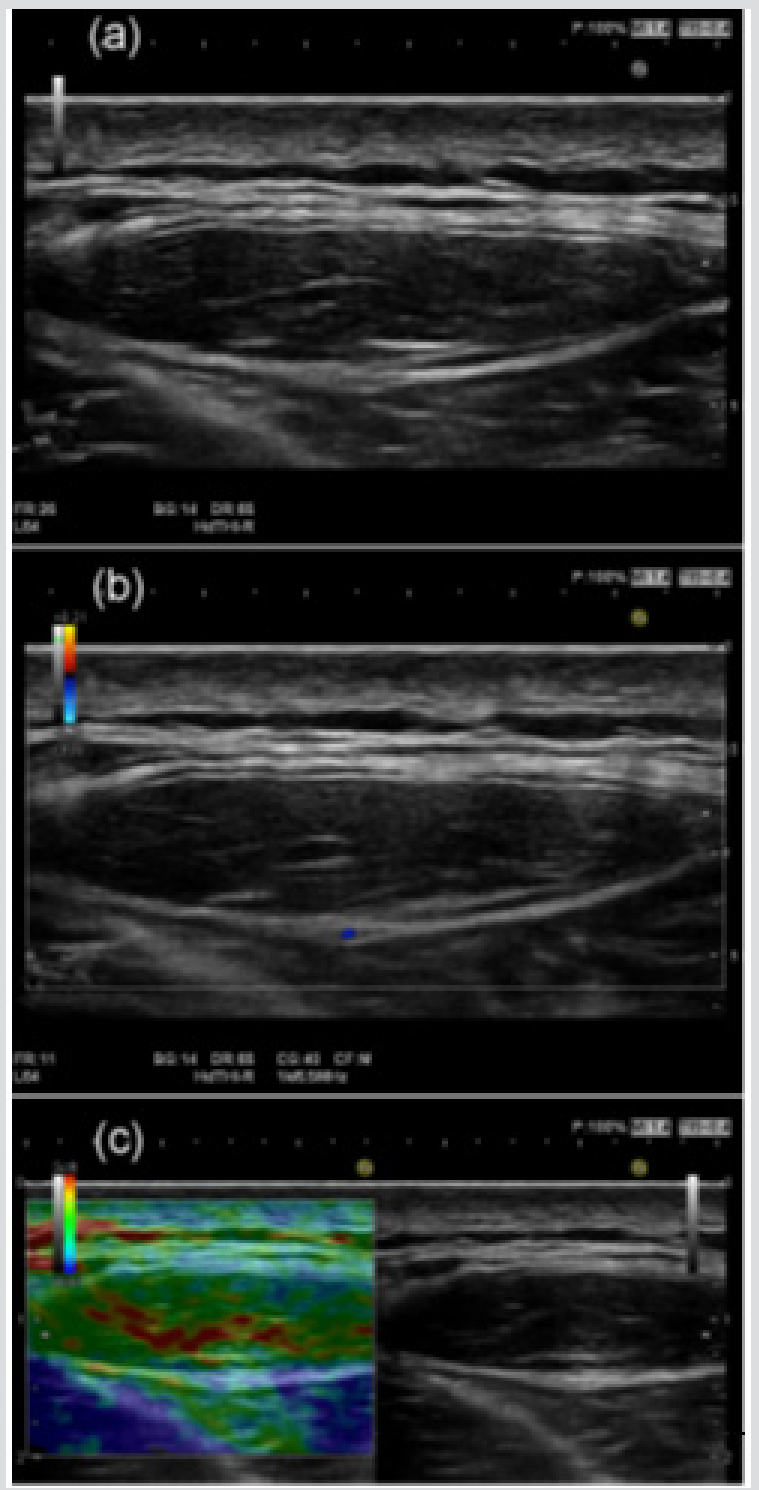

Figure 1: Deep-seated type of lipoma comprehensively diagnosed in the back location in a 66-year-old man. (a) Gray-scale US shows the oblong shape with echogenic lines in the mass. (b) There are no substantial blood flow signals on color Doppler US. (c) Deep-seated lipoma shows green color with a red color, suggesting moderately soft nature, moderately high elasticity on Real-Time Tissue Elastography.

\section{Computed Tomography Features}

It has been reported that the computed tomography (CT) scan feature of intramuscular lipomas shows a hypodense mass situated within the muscle with Hounsfield values in the negative range [17]. They indicated that intramuscular lipomas represent usually ovoid or fusiform in shape and well-circumscribed or poorly defined margins [17]. The intrinsic and extent findings of benign lipomatous lesions are best demonstrated with either CT or MRI [29]. The thick and thin streaks with soft tissue density are generally detected inside the lesion on CT [17]. It has been also described that streaky structures are more distinctive on CT scan than on MRI [30].

\section{Magnetic Resonance Image Features}

It has been reported that T1-weighted MR image shows a homogeneous fat-containing mass, which is similar in signal intensity to the adjacent subcutaneous fat with a thin capsule and thin internal septa in superficial lipoma. It has been also noted that superficial lipoma shows complete suppression of fat signal intensity within the mass, mild enhancement of thin internal septa on post-contrast fat-saturated T1-weighted MR image [31]. While high signal intensity on both $\mathrm{T} 1$ and $\mathrm{T} 2$ weighted images was also demonstrated in the intramuscular type. Like superficial lipoma, fat suppressed sequence shows signal suppression similar to normal fatty tissue. Figure 2a shows high signal intensity mass on axial T2-weighted image. T2-weighted image also shows high signal intensity lesion (Figure 2b). Figure 2c represents complete suppression of fat signal intensity within the mass. 


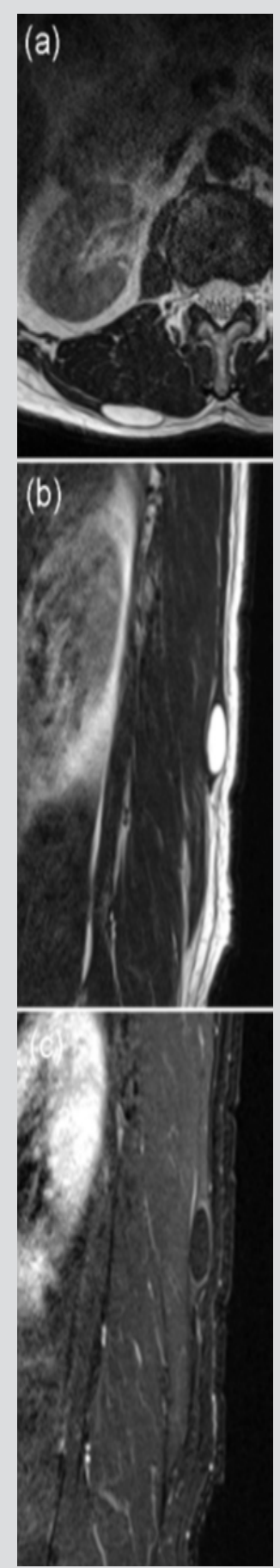

Figure 2: Deep-seated type of lipoma comprehensively diagnosed in the back location in a 66-year-old man. (a) The high signal intensity mass on axial T2-weighted image was observed. (b) T2-weighted image also shows high signal intensity lesion. (c) The fat-saturated T1-weighted MR image represents complete suppression of fat signal intensity within the mass.

\section{Pathological Features}

The pathological diagnostic criteria for lipomas are an abnormal mass or masses composed of mature adipocytes and uniform nuclei that are consistent with those seen in normal adult adipose cells [12]. Adipocytes do not display nuclear atypia. Increased mitosis, hyperchromasia, pleomorphysim or multinucleation of fat cells are not shown. Lipoblasts are not recognized. Individual muscle fibers are normal or often atrophic, but the striking reactive changes are not recognized. In summary, it is plausible that superficial lipomas represent hyperechoic solid mass without posterior echo enhancement on grayscale US. It is putative that both superficial and deep-seated lipomas show echogenic lines in the mass on grayscale US. It is suggested that superficial lipoma mainly show no internal vascular flow, while some of them represented mild and minimal vascular flow on color Doppler US. The author suggests that superficial lipoma shows soft nature, having high elasticity on Real-Time Tissue Elastography. As far as I know, there have been no report of deep-seated lipoma on RTE. In our experience, 
deep-seated lipoma showed green color with a red color, showing moderately soft nature, namely moderately high elasticity on RTE.

\section{Conclusions}

1. The author suggests that superficial lipoma is usually hyperechoic solid mass without posterior echo enhancement on the gray-scale ultrasonography.

2. It is plausible that both superficial and deep-seated lipomas show echogenic lines in the mass on gray-scale ultrasonography.

3. The author will suggest that deep-seated lipoma show moderately soft nature, having moderately high elasticity on Real-Time Tissue Elastography.

\section{Acknowledgement}

The author appreciates Dr. Akira Fujioka, Dr. Minoru Oishi, Dr. Ken Hayashi and Dr. Masahiro Okada.

\section{References}

1. Wortsman X, Alfageme F, Roustan G, Arias Santiago S, Martorell A, et al. (2016) Guidelines for performing dermatologic ultrasound examinations by the DERMUS group. J Ultrasound Med 35(3): 577-580.

2. Wortsman X, Alfageme F, Roustan G, Arias Santiago S, Martorell A, et al (2016) Proposal for an assessment training program in dermatologic ultrasound by the DERMUS group. J Ultrasound Med 35(11): 2305-2309.

3. Elbardouni A, Kharmaz M, Berrada MS, Mahfoud M, Elyaacoubi M (2011) Well-circumscribed deep-seated lipomas of the upper extremity. A report of 13 cases. Orthop Traumatol Sur Res 97(2): 152-158.

4. Fujioka K, Fujioka A, Eto H, Suzuki K, Sanuki E, et al. (2006) Nodular fascitis in the thigh followed up using ultrasonography. J Med Ultrason 33(1): 49-53.

5. Fujioka K, Fujioka A, Oishi M, Eto H, Tajima S, etal. (2017) Ultrasonography findings of intradermal nodular fasciitis; a rare case report and review of the literature. Clin Exp Dermatol 42(3): 335-336.

6. Fujioka K, Fujioka A, Tajima S, Oishi M, Hayashi K, et al. (2018) Characteristic power Doppler sonographic imaging of nodular fasciitis from dermatological perspective: another case and review of three cases. J Clin Case Rep 8(9): 1165.

7. Fujioka K, Fujioka A, Oishi M, Hayashi K, Nakayama T (2018) Highresolution ultrasound imaging for angioleiomyoma: a painful and vascularized superficial tumor. Biomed J Sci \& Tec Res 9(5): 7383-7386.

8. Fujioka K (2018) Presentations of clinical, ultrasonographic and pathological features of nodular fasciitis from an established cytogenetic viewpoint: review of the cases. J Carcinog Mutagen 9(4): 326.

9. Fujioka K (2018) Usefulness of comprehensive high-resolution ultrasound imaging in dermatologic field: epidermal cyst. Biomed J Sci \& Tec Res 12(1): 8917-8920.

10. Fujioka K (2019) Painful cutaneous and subcutaneous tumors accompanied with vascularized appearance using high-resolution ultrasound in dermatology: the acronym "ENGLAND" or "LEND AN EGG". Biomed J Sci \& Tec Res 12(4): 9449-9453.

11. Fujioka K (2019) Real- time Tissue elastography in epidermal cyst: along with enhanced MRI and elasticity features of peripheral rim. Biomed ] Sci \& Tec Res 16(5).

12. Shin YS, Kim YJ, Park IS, Chu YC, Kim JH, et al. (2016) Sonographic differentiation between aniolipomas and superficial lipomas. I] Ultrasound Med 35(11): 2421-2429.

13. Wagner JM, Lee KS, Rosas H, Kliewer MA (2013) Accuracy of sonographic diagnosis of superficial masses. J Ultrasound Med 32(8): 1443-1450.
14. Paunipagar BK, Griffith JF, Rasalkar DD, Chow LTC, Kumta SM, et al. (2010) Ultrasound features of deep-seated lipomas. Insights Imaging 1(3): 149-153.

15. Mandahi N, Bartuma H, Magnusson L, Isaksson M, Macchia G, et al. (2011) HMGA2 and MDM2 expression in lipomatous tumors with partial, lowlevel amplification of sequences from the long arm of chromosome 12. Cancer Genet 204(10): 550-556.

16. Lacaria M, El Demellawy D, McGowan Jordan J (2017) A rare case of pediatric lipoma with $\mathrm{t}(9 ; 12)(\mathrm{p} 22 ; \mathrm{q} 14)$ and evidence of HMGA2-NFIB gene fusion. Cancer Genet 216-217: 100-104.

17. McTighe S, Chernev I (2014) Intramuscular lipomas: a review of the literature. Orthopedic Reviews 6(4): 5618

18.Zamora MA, Zamora CA, Samayoa EA, Morales HA, Ceballos JF (2005) High-resolution ultrasonography in an aggressive thenar intramuscular lipoma. J Ultrasound Med 24(8): 1151-1155.

19. Ahuja AT, King AD, Kew J, King W, Metreweli C (1998) Head and neck lipomas: sonographic appearance. AJNR 19(3): 505-508.

20. Inampudi P, Jacobson JA, Fessell DP, Carlos RC, Patel SV, et al. (2004) Softtissue lipomas: accuracy of sonography in diagnosis with pathologic correlation. Radiology 233(3): 763-767.

21. Hwang EJ, Yoon HS, Cho S, Park HS (2015) The diagnostic value of ultrasonography with 5-15-MHz probes in benign subcutaneous lesions. Int J Dermatol 54(11): e469-475.

22. Hung EHY, Griffith JF, Ng AWH, Lee RKL, Lau DTY, et al. (2014) Ultrasound of musculoskeletal soft-tissue tumors superficial to the investing fascia. AJR 202(6): W532-W540.

23. Kuwano Y, Isihizaki K, Watanabe R, Nanko H (2009) Efficacy of diagnostic ultrasonography of lipomas, epidermal cysts, and ganglions. Arc Dermatol 145(7): 761-764.

24. Rahmani G, McCarthy P, Bergin D (2017) The diagnostic accuracy of ultrasonography for soft tissue lipomas: a systematic review. Acta Radiologca Open 6(6): 1-6.

25. Itoh A, Ueno E, Tohno E, Kamma H, Takahashi H, et al. (2006) Breast disease: clinical applications of US elastography for diagnosis. Radiology 239(2): 341-350.

26. Klauser AS, Miyamoto H, Bellmann Weiter R, Feuchtner GM, Wick MC, et al. (2014) Sonoelastography: musculoskeletal applications. Radiology 272(3): 622-633.

27. Lee YH, Song HT, Suh JS (2014) Use of strain ratio in evaluating superficial soft tissues tumors on ultrasonic elastography. J Med Ultrason 41(3): 319-323.

28. Park HJ, Lee SY, Lee SM, Kim WT, Lee S, et al. (2015) Strain elastography features of epidermoid tumours in superficial soft tissue: differences from other benign soft tissue tumours and malignant tumours. $\mathrm{Br}$ J Radiol 88(1050): 20140797.

29. Murphey MD, Carroll JF, Flemming DJ, Pope TL, Gannon FH, et al. (2004) From the archives of the AFIP: benign musculoskeletal lipomatous lesions. Radiographics 24(5): 1433-1466

30. Nishida J, Morita T, Ogose A, Okada K, Kakizaki H, et al. (2007) Imaging characteristics of deep-eated lipomatous tumors: intramuscular lipoma, intermuscular lipoma, and lipoma-like liposarcoma. J Orthop Sci 12(6): 533-541.

31. Gupta P, Potti TA, Wuertzer SD, Lenchik L, Pacholke DA (2016) Spectrum of fat-containing soft-tissue masses at MR imaging: the common, the uncommon, the characteristic, and the sometimes confusing. Radiographics 36(3): 753-766. 
ISSN: 2574-1241

DOI: 10.26717/BJSTR.2019.19.003278

Kazumi Fujioka. Biomed J Sci \& Tech Res

(c) (P) This work is licensed under Creative

Submission Link: https://biomedres.us/submit-manuscript.php

\begin{tabular}{ll} 
BIOMEDICAL & \multicolumn{1}{c}{ Assets of Publishing with us } \\
RESEARCHES & - Global archiving of articles \\
- Immediate, unrestricted online access \\
- Rttps://biomedres.us/
\end{tabular}

